\title{
Experimental and Numerical Study of a Heat Pipe Based Indirect Porous Ceramic Evaporative Cooler
}

\author{
R. Boukhanouf, A. Alharbi, O. Amer, and H. G. Ibrahim
}

\begin{abstract}
Indirect evaporative coolers are one of the most possible alternatives to conventional cooling methods for building air-conditioning. It utilizes evaporation of water to cool the air, consumes much less power, and employs no harmful refrigerants comparing to other traditional cooling cycles such as vapor compression coolers. This paper presents a mathematical model and experimental investigation of thermal performance of an indirect porous ceramic evaporative cooler with integrated heat pipe for heat transfer. It is shown that good agreement was achieved between the computer model and measured parameters of the cooling system. In the regions with hot and dry climates the system can be an environmentally friendly and energy efficient cooling system.
\end{abstract}

Index Terms-Indirect evaporative cooling, heat pipe, porous ceramic, dew-point effectiveness.

\section{INTRODUCTION}

Buildings air-conditioning loads have increased considerably in the recent decades both in residential and commercial buildings, leading to a proportionate rise in energy consumption in buildings. In most developed countries, buildings use between 40 to $50 \%$ of primary energy with HVAC systems being responsible for a large portion of the building's energy demand, particularly cooling loads in hot and humid regions [1]. Given that that most of this energy is sourced from conventional fossil fuel reserves, it is becoming increasingly apparent that providing comfort conditions in buildings in this manner is not sustainable in the long run. For example, in addition to escalating energy prices, the environmental impact of buildings relates to about a third of global carbon. Off this amount, about $80 \%$ carbon emission is directly related to electricity consumption for buildings air-conditioning systems [2].

In the current market of buildings cooling, mechanical vapour compression coolers are the dominant despite their massive energy consumption and low thermal performance in hot climates. Hence, there is urgency in finding less energy intensive method for cooling in buildings. One method adopted by ancient civilization is to use water evaporation for cooling. Evaporative cooling systems perform more efficiently with reasonable cooling capacities particularly in

Manuscript received May 4, 2014; revised June 10, 2014. This publication was made possible by NPRP grant No. 4-407-2-153 from the Qatar National Research Fund (a member of Qatar Foundation). The statements made herein are solely the responsibility of the authors.

R. Boukhanouf, A. Alharbi, and O. Amer are with The University of Nottingham, Department of Architecture and Built Environment, Nottingham, NG7 2RD, UK (e-mail: rabah.boukhanouf@nottingham.ac.uk, laxaa17@nottingham.ac.uk, ezxoea@nottingham.ac.uk ).

H. G. Ibrahim is with Qatar University, Department of Architecture and Urban Planning, Doha, Qatar (e-mail: hatem_ibrahim@qu.edu.qa). hot and dry climates. Table I shows a comparison of the properties of Vapour Mechanical Compression (VMC) cooling, desiccant cooling and evaporative cooling systems. It is shown that though VMC systems have higher COP than other technologies the negative environmental impact is huge. Evaporative cooling systems on the other hand have low environmental impact but the performance is strongly dependent on prevailing climatic conditions particularly the temperature difference between the dry-bulb and wet-bulb of the ambient air. For hot and dry climates this temperature difference is large, resulting high cooling effectiveness.

\section{Evaporative CoOling Technology}

Evaporating cooling is a heat and mass transfer process which involves water evaporation into the surrounding air and large amount of heat exchange between air and exposed water surface. As air flows over the water surface, it loses its sensible heat to the water causing it to evaporate and consequently reducing the air temperature and increasing its moisture content. Evaporative coolers could be classified into: 1) Direct evaporative cooling systems (DEC), where the working fluids are in direct contact; 2) Indirect evaporative cooling systems (IEC), where a heat transfer surface separates between the working fluids; 3 ) Combined systems which are a hybrid configurations of DEC and IEC or with other cooling cycles [3].

\section{A. Direct Evaporative Cooling Systems (DEC)}

These systems are one of the oldest and simplest buildings cooling systems. Today, they still can be found in many parts of the world integrated into traditional architecture using earthenware jar water contained and wetted fabrics located in air supply passages and in modern buildings as standalone units manufactured using modern processes and materials.

TABLE I: A GENERAL COMPARISON BETWEEN THE SOME AIR-CONDITIONING SYSTEMS

\begin{tabular}{llll}
\hline \hline \multirow{2}{*}{ System type } & $\begin{array}{l}\text { VMC } \\
\text { cooling }\end{array}$ & $\begin{array}{l}\text { Desiccant } \\
\text { cooling }\end{array}$ & $\begin{array}{l}\text { Evaporative } \\
\text { cooling }\end{array}$ \\
\hline COP & 2 to 3 & 0.6 to 1.2 & 15 to 20 \\
Power consumption & High & Medium & Medium \\
Refrigerants & CFCs, & Solid/liquid & Water \\
Environmental Impact & Exiccants & \\
\hline \hline
\end{tabular}

A typical configuration of direct evaporative cooler, as shown schematically in Fig. 1a, comprises of evaporative media (Pads) from wettable and porous materials, fan blows air through the wetted medium, water tank, recirculation pump and water distribution system. The direct evaporative cooling is an adiabatic cooling process of the supply air as the 
water is in contact with it, i.e. the total enthalpy of the air is constant throughout the process, as shown in Fig. 1b. The water absorbs the sensible heat from the supply air and evaporates. So the air temperature decreases and simultaneously water vapour is carried away by the cooled air to the conditioned space [4]. Theoretically, the supply air could be cooled to $100 \%$ saturation, but often the wet-bulb effectiveness is limited to $70-80 \%$. This mainly affected by the the air supply wet-bulb temperature, short contact time between the water surface and the air (insufficient wettability of the evaporative pad) [5].

\section{B. Indirect Evaporative Cooling Systems (IEC)}

Unlike DEC, this arrangement was conceived from the need to cool air without increasing its moisture content. A typical IEC unit, as illustrated in Fig. 2a, comprises of: a heat exchanger, small fan, pump, water tank, and water distribution lines. Fig. 2b shows a schematic drawing of the working principles of a typical IEC system which comprises of pairs of adjacent channels: wet passages of the working air and dry passages of the supply air. Heat transfer occurs between the two working fluids indirectly through a heat conductive plate without any mixing of both air streams, therefore, the supply air is cooled sensibly with no additional moisture introduced into the cooled air stream. While, heat transfer mechanism between the working air and water in wet channels is by latent heat of water vaporisation [6].

Based on the cooling temperature range of the primary air that can be achieved, indirect evaporative coolers are divided into: Wet-bulb temperature IEC systems and Sub wet-bulb temperature ICE systems. The wet-bulb effectiveness of the IEC is lower than that of the DEC system, which ranges from 40 to $60 \%$ [3].

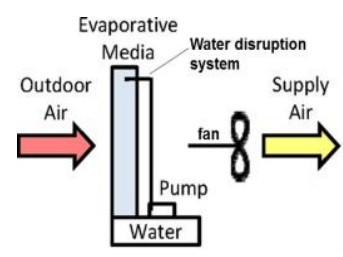

(a) Main components of DEC system

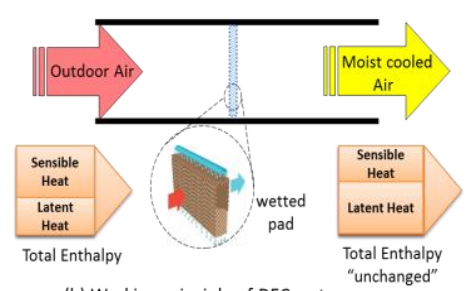

(b) Working principle of DEC system
Fig. 1. DEC system structure and working principle [6].

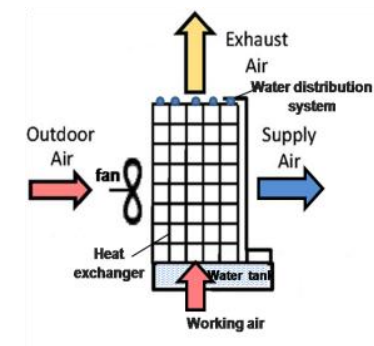

(a) Structure of IEC

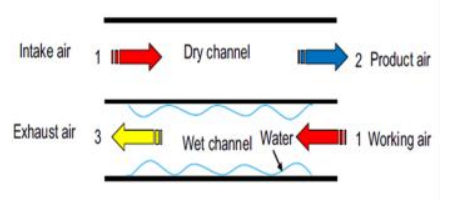

(b) Working principle
Fig. 2. IEC system structure and working principle [6].

The current focus is directed towards high thermal performance sub-wet bulb temperature evaporative cooling (enhanced cooling capacity and cooling supply air to near dew point temperature) using modified component arrangements of the wet-bulb IEC system and advanced surface coating materials. For example, Maisotsenko [7] introduced the (M-cycle) which is a novel design of the heat exchanger of IEC system to overcome some of the disadvantages of DEC systems and enhance the effectiveness of wet-bulb temperature IEC. The M-cycle based IEC system is a combination of a cross-flow, multi-perforated flat-plate heat exchange and evaporative cooling, in which, the working air is precooled in the dry channel before it is diverted to pass through the wet channel to achieve further heat transfer with the dry channel. So that the product air temperature is lower than wet-bulb temperature and approach dew-point temperature of the incoming air (it is also referred to as Dew point IEC systems). The M-cycle achieves wet-bulb effectiveness is in the range of $110 \%-122 \%$ and a dew-point effectiveness approaching 100\%. Elberling [8] experimentally evaluated the performance of a Coolerado Cooler which is an M-cycle based indirect evaporative cooling unit. It was found that the wet-bulb effectiveness ranged $81 \%-91 \%$ during all test conditions which is less than theoretical effectiveness $(100 \%)$.

Zhao et al. [9] introduced a new counter-flow heat and mass exchanger based on M-cycle of a dew-point evaporative cooling system. In this structure, unlike the cross-flow Maisotsenko-cycle HX, holes are located at end of flow channels as presented in Fig. 3. The product air flows through and along the dry channels losing sensible heat to wet channels and at the end of dry channels part of cooled product air is delivered to conditioned space and the remaining air is diverted to the adjacent wet channels as cold working air travelling on a counter-flow direction to the dry air and transferring heat latently with the water. It was found that the wet bulb effectiveness achieve up to $130 \%$ and dew-point effectiveness of up to $90 \%$. Furthermore, a comparative study between cross-flow and counter-flow M-cycle based IEC system showed that the counter-flow arrangement achieved around $20 \%$ higher cooling capacity and $15-23 \%$ higher dew-point and wet-bulb effectiveness respectively under the same geometrical sizes and operational conditions. However, this performance enhancement is offset by an increase in power consumption of about $10 \%$. [10]. The authors [11] and [12] also reported that cooler water consumption rate ranged from 2.1 to 3 $1 / \mathrm{kWh}$ and its cooling output ranged of $3.1-4.3 \mathrm{~W} / \mathrm{m}^{3} / \mathrm{h}$ air flow rate.

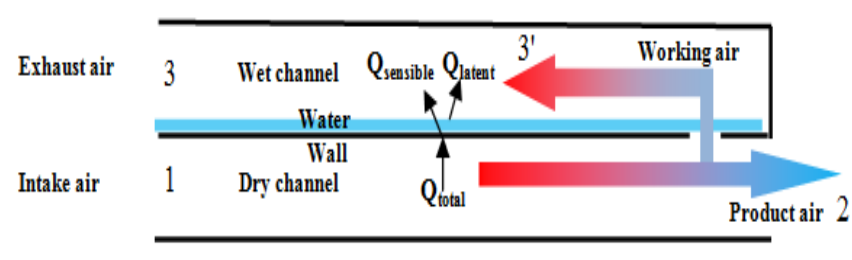

Fig. 3. A schematic of a sub wet-bulb IEC based on M-cycle [9].

Riangvilaikul and Kumar experimentally [6] and theoretically [13] investigated the performance of a novel counter-flow, flat-plate-type dew-point evaporative cooler based on M-cycle at different inlet air conditions and for various climate conditions. The results showed that wet-bulb effectiveness ranged from 92 to $114 \%$ and the dew-point effectiveness ranged between 58\%-84\%. It was recommended that the inlet air velocity is below $2.5 \mathrm{~m} / \mathrm{s}$, channel height less than $5 \mathrm{~mm}$, channel length larger than $1 \mathrm{~m}$ 
and ratio of working-to-intake air be around 35-60\% to maintain the wet bulb effectiveness greater than $100 \%$.

Cui et al. [14] theoretically investigated the thermal performance of a counter-flow closed-loop flat-plate-stacked heat exchanger of a dew-point evaporative cooler under varying inlet conditions. Additionally, they studied the effect of the channels surface roughness and effect of using the return air from conditioned space as working air on the overall performance of the system. The wet bulb effectiveness spanned from $122 \%$ to $132 \%$ and dew-point effectiveness ranged from $81 \%-93 \%$. Additionally, it was found that the effectiveness could be effectively increased by 10-20\%, if the room return air was used as working air, and also when roughness of channels surface were applied with inlet air velocity higher than $1.5 \mathrm{~m} / \mathrm{s}$.

Rogdakis et al. [15] evaluated the theoretical and experimental performance characteristics of an M-cycle based IEC system at Greek climate condition. It was found that the Maisotsenko cycle can be applied for most Greek cities without intensive consuming of electricity and water, the effectiveness ranged between $97 \%$ and $115 \%$, while water consumption was in the range of $2.53 .0 \mathrm{~L} \mathrm{kW/h}$.

\section{Wet Media Materials of IEC Systems}

Wet media materials have significant influence on the performance of IEC system. Unlike the DEC system, heat transfer occurs indirectly via a wall surface which interfaces between wet and dry channels of IEC system. Therefore, it is desirable that wet media should have high thermal conductivity, uniform water wettability, large contact area, and good coating compatibility to enable sufficient water evaporation, on the wet-side channel, and thus enhance the sensible and latent heat exchange on both sides of the channels. A study of several types of water wicking materials of evaporative cooling systems found that the shape formation, durability, compatibility with coating material, contamination risk and cost of materials are most important selection criteria of the wet media materials [16].

In general, Limited research activities have been found on the use of porous ceramic materials systems as wetting pads for evaporative cooling applications [17]-[22]. Nevertheless, porous ceramic is considered to be a promising material in heat transfer augmentation [23]. It was employed hundreds of years ago for several cooling purposes, e.g. for building cooling, drinking water cooling and food preservation [1]. Recently, porous ceramic has drawn the attention for IEC system cooling applications in buildings. Owing to their durability, accessibility, good thermal conductivity, availability in different porosities, sufficient water-retaining capacity, and high contact surface between solid and fluid phases. However, relatively high prices and possibility of bacteria growth are the down side of employing porous ceramic in IEC systems [16]. Riffat and Zhu [24] employed porous ceramic as wetting pad of a heat pipe based indirect evaporative cooler with water-filled ceramic container was fitted around the pear pipe condensation section to assure even distribution of water. Similarly, Boukhanouf et al. [25] used closed, hollow, rectangular porous ceramic panels as heat transfer wall of a dew-point IEC system, as shown in Fig. 4a. The results showed that the average wet-bulb effectiveness was $117 \%$. Furthermore, Gómez et al. [26] fabricated and experimentally tested finned tubes heat and mass exchanger of an indirect evaporative cooler, the pipes were made from a porous ceramic material, as illustrated in Fig. $4 b$, the device acts as a recovery system of air conditioning systems.

\section{Heat Pipe Heat Exchanger Based Wet-Bulb IEC Systems}

Heat pipe is a light, simple, reliable and high conductive heat transfer element available in different types, configurations, sizes. In the literature many research studies conducted on heat pipes applications in building cooling including HVAC systems [27], heat recovery systems [28], dehumidification enhancement of air conditioning systems [29]. But only limited research work on the applications of heat pipes in indirect evaporative cooling systems for building cooling, that is reviewed as follows: Riffat and Zhu [24] introduced new configuration of indirect evaporative cooling system incorporating horizontal heat pipe. This system consists of two adjacent channels one for indoor-air and another for outdoor-air and conventional heat pipe is fitted horizontally cross both passages. A porous ceramic water container fitted around the hot end of the heat pipe (condensation section) to assure even distribution of water, and on the cold end side (evaporation section of the heat pipe) fins are fitted on to increase convective heat transfer between the heat pipe fins and surrounding indoor air. Fig. 5a shows a schematic drawing of proposed evaporative cooling system. The results showed that the system efficiency increased by $30 \%$ compared with any typical IEC system. Also, Xuan et al. [5] in their review referred to different designs of heat pipe based IEC systems in China which were the same configuration proposed by [24] apart from the use of water sprayers on the heat pipe condensation section wrapped with a thin layer of water absorption material instead of using ceramic container, as shown in Fig. 5b. According to their findings an effectiveness of $70 \%$ was achieved which crested an average of $10^{\circ} \mathrm{C}$ temperature difference between the heat pipe and airstreams.

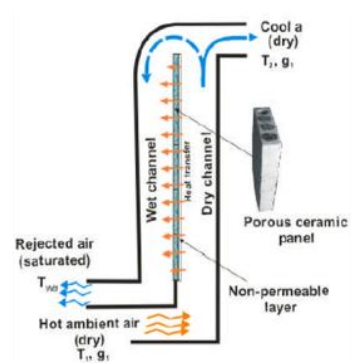

(a) Ceramic panels dew-point IEC

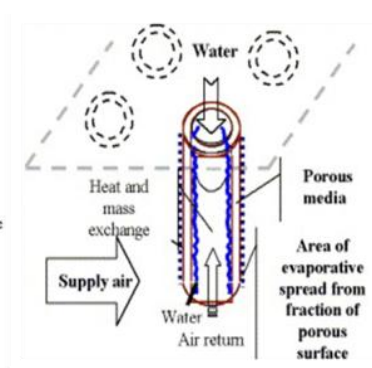

(b) Finned ceramic tubes IEC
Fig. 4. Schematics of IEC systems incorporating porous ceramic materials as wet media [25], [26].

Moreover, the authors presented four new configurations of heat pipe based IEC systems, which are: 1) the outdoor air is used for cooling heat pipe condensation section (Fig. 6a), 2 ) the outdoor air is precooled by air washer before passed through the condensation section of the heat pipe (Fig. 6-b), 3) the outdoor air is precooled by DEC unit then flowed through the heat pipe condensation section (Fig. 6c), 4) the outdoor air is flowed through the heat pipe condensation 
section and water is sprayed on the top of condensation section surface (Fig. 6d). It was found that configuration 4 had best cooling capacity and higher efficiency than other configurations of $7-16 \%$

\section{Design of HeAt Pipe Indirect Ceramic Evaporative COOLER}

\section{A. Description}

In this work, porous ceramic cylinders were used as wet media of a counter-flow, heat pipe based IEC system for buildings cooling. A detailed schematic diagram of a new configuration is shown in Fig. 7; the system consists of two adjacent channels separated by a heat conductive, non-permeable thin wall. Heat pipes are placed vertically across wet and dry channels for heat transfer. Fins are fitted on the evaporation section of each heat pipe to increase heat transfer from the air dry channel via heat pipes to the wet channels. While heat dissipation mechanism in the wet channel employs porous ceramic cylinder fitted around the heat pipe's condensation section and filled with water, in order to assure sufficient and even distribution of water for the whole condensation surface of the heat pipe.
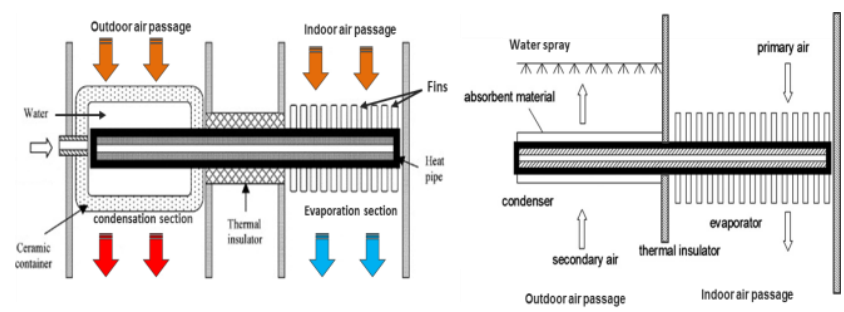

$\begin{array}{ll}\text { (a) Heat pipe and porous ceramic container based IEC system } & \text { (b) Heat pipe and water sprayer based IEC system }\end{array}$

Fig. 5. Schematic of two configuration of Heat pipe based IEC system [24], [5].
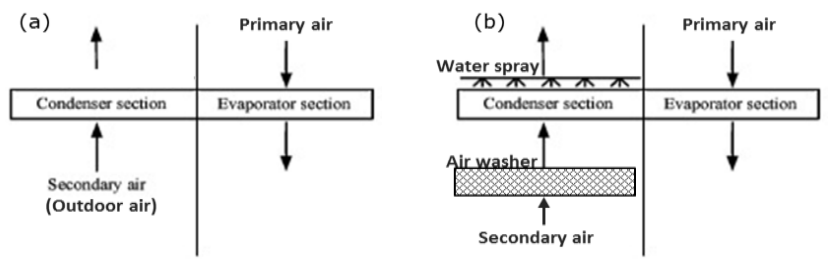

(c)
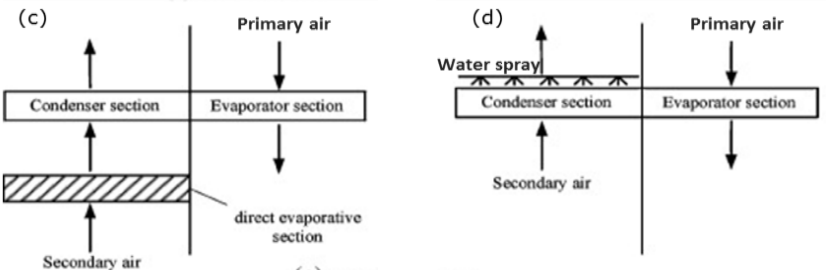

Fig. 6. Schematic of different configuration of Heat pipe based IEC [5].

The water can be easily supplied at the top of wet channel and it flows down to fill the gap between the heat pipe surface and ceramic cylinder which will be saturated and sips the water through its micro-pores onto its outer surface forming a thin water film. This allows direct contact with the working air and hence causing water evaporation. In the process of this configuration, the primary air is cooled sensibly by heat transfer through the separation wall to the wet channels and via heat pipes to the water in the porous ceramic cylinders that in turn is cooled through water evaporation on the wet channel side. This results in a drop in temperature of the air in the dry channel without changing its humidity while the air in the wet channel is rejected at saturation state.

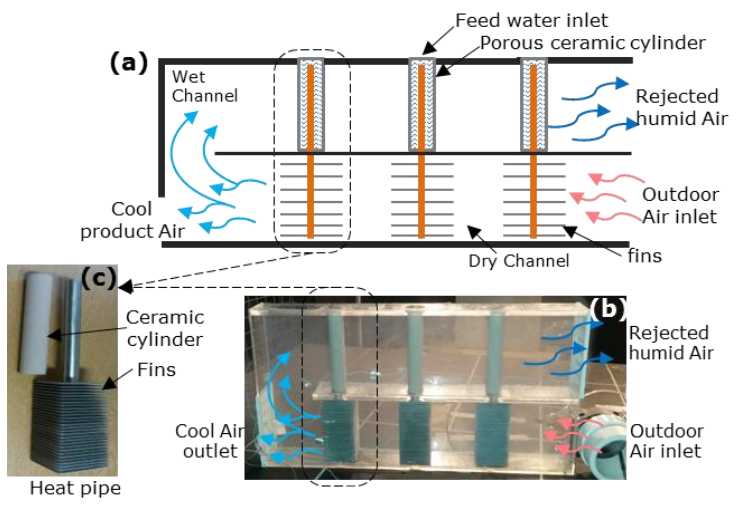

Fig. 7. A schematic of the Heat pipe based porous ceramic IEC system.

\section{B. Small Scale Experimental Set-up and Procedure}

The primary aim of this experiment is to evaluate the thermal performance of the heat pipe based IEC system. To achieve that a prototype unit, presented in Fig 7b, was built and tested under various climates and ambient air conditions. The basic specifications used for the fabricated heat and mass exchanger are summarized in Table II. The Heat pipe based IEC experimental rig was equipped with a variable speed fan to draw the air at controlled temperature and humidity from an environmental chamber and blow throughout the test-rig, while water is drawn from an overhead tank. Ten thermocouples were installed at several points of the device to measure temperature. Data logger was used to record readings during the experiment and save the data on a computer.

\section{Mathematical Model}

\section{Heat and mass transfer model}

The variation of the temperature and moisture content in the dry and wet channels can be determined from the equation of heat and mass transfer conservation. In the dry channel air is cooling by transferring its sensible heat to the heat pipe wall and fins at constant air moisture content.

TABLE II: BASIC SPECIFICATIONS OF THE DIMENSIONS OF THE IEC SYSTEM

\begin{tabular}{lc}
\hline \hline Parameters & Specification/value \\
\hline Wall thickness & $0.4 \mathrm{~mm}$ \\
Channel length & $520 \mathrm{~mm}$ \\
Channel width & $60 \mathrm{~mm}$ \\
Channel height & $150 \mathrm{~mm}$ \\
Number of heat pipes & 3 \\
\hline \hline
\end{tabular}

On the other hand, the air flow temperature and moisture content change along the wet channel and emerge at saturation conditions at the duct outlet. In this work each heat pipe-ceramic tube module is considered as a homogeneous control volumes. The air flow duct is divided into three control volumes to match the number of heat pipe-ceramic tubes modules. Fig. 8 shows a cross section of such a module.

The heat transfer in the dry channel is given by: 


$$
\dot{m}_{d} c_{p d} d T_{d}=U\left(T_{d}-T_{f w}\right) d A
$$

where, $m_{d}$ is the air mass flow rate in the dry channel, $C_{p d}$ is the specific heat of the air, $\mathrm{A}$ is the heat transfer area, $\mathrm{U}$ is the overall heat transfer coefficient between the two air flows, Td is the average temperature in the dry channel, $T_{f w}$ is the average temperature of water film and $U$ is the overall heat transfer coefficient which is given by:

$$
U=\frac{1}{\Sigma R},
$$

where $\Sigma R$ is the total thermal resistance of heat pipe and ceramic tube shown in Fig. 8.

The heat transfer mechanism in the wet channel is more complicated than in the dry channels, as sensible and latent heat are exchanged between the airflow and the water film on the surface of the porous ceramics. This is given by Halasz [30] as follows:

In the wet channel, the air flow temperature variation is expressed as:

$$
\dot{m}_{a} c_{p a} d t_{a}=\alpha_{a}\left(T_{f w}-t_{a}\right) d A_{a}
$$

where, $m_{a}$ is the air mass flow rate in the wet channel, $\alpha_{a}$ is the overall heat transfer coefficient between the two air channels, $A_{a}$ is the heat transfer area, $t_{a}$ is the average temperature in the wet channel, $T_{f w}$ is the average temperature of water film.

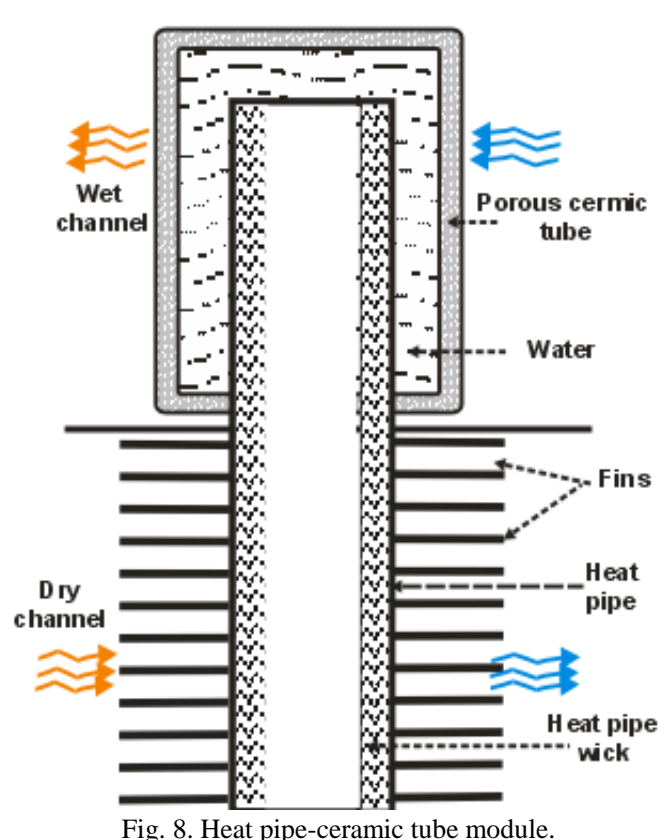

Similarly, the vapor mass transfer from the ceramic surface is driven by the vapour partial pressure difference. This expressed as:

$$
m_{a} d g_{a}=\sigma\left(g_{f w}-g_{a}\right) d A_{a}
$$

where, $\sigma$ is the mass transfer coefficient, $g_{f w}$ is the moisture content at saturation, $g_{a}$ is the average moisture content of air in the wet channel.
The relationship between heat transfer and mass transfer coefficient in the wet channel is often expressed by Lewis number. This is can be given as:

$$
\frac{\alpha_{a}}{\sigma}=\rho c_{p a} L e^{2 / 3}
$$

It is assumed that the air flow in the narrow channels is in laminar regime and Lewis number is often in the range of 0.9 to 1.15 and to simplify the model it was taken to be 1 [30].

\section{RESUlTS AND DisCUSSION}

\section{A. Results}

The airflow temperature profile along the dry and wet channels is given in Fig. 9. The computer model predicts that the airflow in the dry channel would be cooled to $25.3{ }^{\circ} \mathrm{C}$ while the temperature of the airflow along the wet channel decreased from $25.3{ }^{\circ} \mathrm{C}$ to $22.5{ }^{\circ} \mathrm{C}$. Similarly the experimental measurements show the air temperature at the outlet of the dry channel is about $26.4{ }^{\circ} \mathrm{C}$ and that of the wet channel is 25.7 . It is to be noted that the air temperature in the wet channel did not reach saturation conditions as it would require a larger wet surface area. This explains the continuous temperature reduction in the wet channel. The difference between the measured and computer model results are mainly due to the heat loss from the air duct to the surrounding.

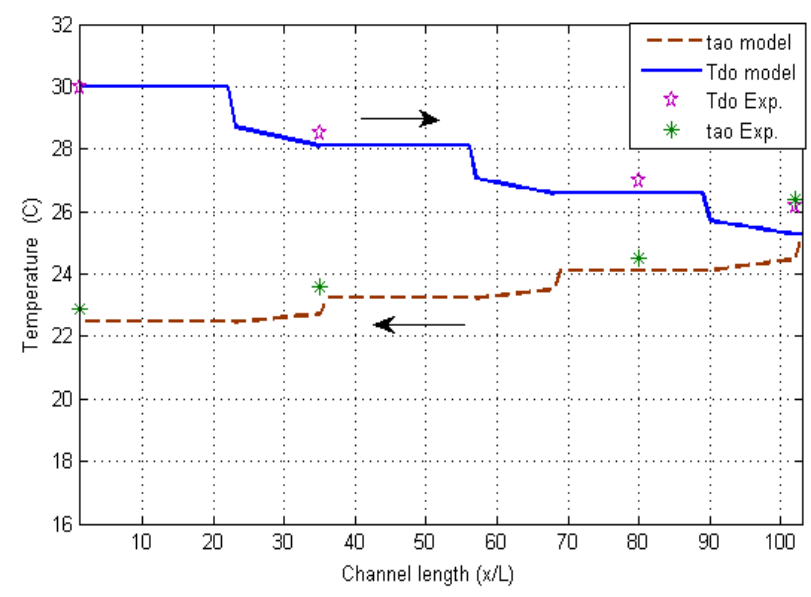

Fig. 9. Air temperature variation in the dry and wet channel.

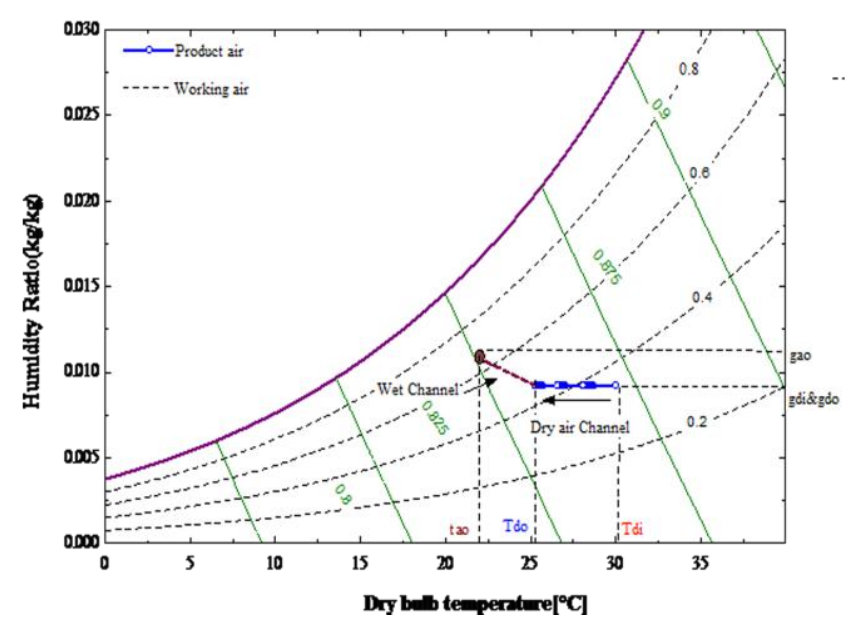

Fig. 10. Air operating properties. 
Fig. 10 shows the operating properties of the airflows in the dry and wet channels. It is shown that the outlet air temperature of the dry channel is cooled by about $5^{\circ} \mathrm{C}$ where the temperature drops from 30 to $25^{\circ} \mathrm{C}$. Again, it can be seen that the airflow outlet in the wet channel did not reach the saturation line.

Furthermore, the cooling capacity and wet bulb effectiveness of the evaporative cooler were determined at various inlet air relative humidity conditions $(35 \%, 40 \%$, $45 \%, 50 \%$ and $55 \%$ ) and two different ambient temperatures $\left(30\right.$ and $35{ }^{\circ} \mathrm{C}$ ). The dry channel air flow rate remaining constant at $0.003 \mathrm{~kg} / \mathrm{s}$. Fig. 11 shows that the cooling capacity is strongly influenced by relative humidity and is inversely proportional. Similarly the cooling capacity decreased with increasing inlet relative humidity.

Fig. 12 shows the wet bulb effectiveness of inlet air temperature 30 and $35^{\circ} \mathrm{C}$. It can be see that both of them slightly decreased with increasing relative humidity and higher inlet temperature give higher effectiveness.

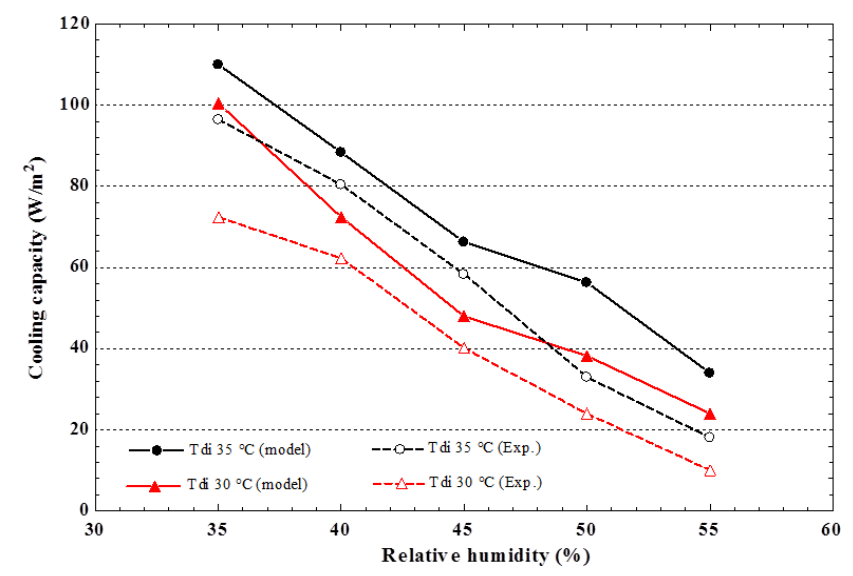

Fig. 11. Cooling capacity $\left(m_{d}=0.003 \mathrm{~kg} / \mathrm{s}\right)$.

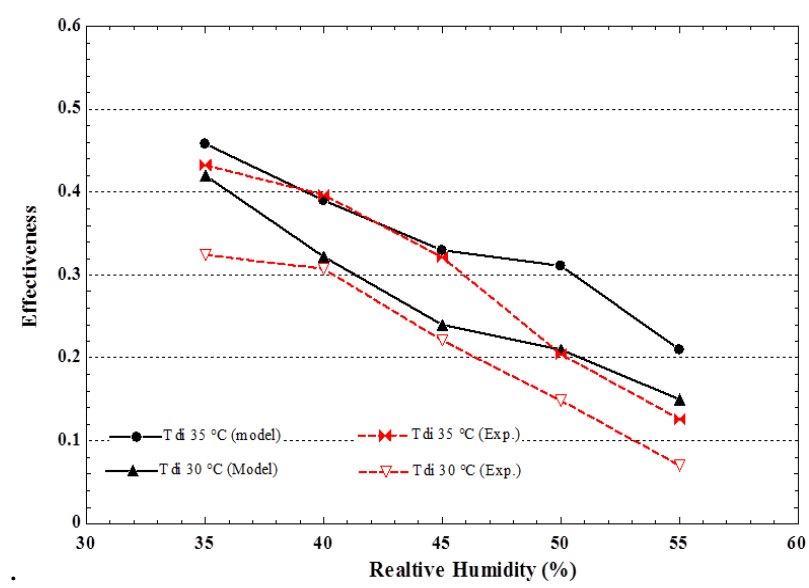

Fig. 12. Effectiveness $\left(m_{d}=0.003 \mathrm{~kg} / \mathrm{s}\right)$.

\section{CONCLUSION}

An integrated small scale heat pipe-ceramic evaporative cooler has been studied and the experiment and computer results presented. The result mainly depicts that the ceramic wet area available was not sufficient for the airflow in the wet channel to reach saturation conditions. However, the idea of using heat pipes presents a number of advantages in that effective heat transfer between the two air flows has been achieved. A dry bulb temperature of the air flow in the dry channel dropped by $5{ }^{\circ} \mathrm{C}$ though the effectiveness was moderate.

\section{REFERENCES}

[1] M. Sivak, "Potential energy demand for cooling in the 50 largest metropolitan areas of the world: Implications for developing countries," Energy Policy, vol. 37, no. 4, pp. 1382-1384, 2009.

[2] V. Vakiloroaya et al., "A review of different strategies for HVAC energy saving," Energy Conversion and Management, vol. 77, pp. 738-754, 2014.

[3] Z. Duan et al., "Indirect evaporative cooling: Past, present and future potentials," Renewable and Sustainable Energy Reviews, vol. 16, no. 9, pp. 6823-6850, 2012.

[4] J. R. Watt, W. K. Brown, and R. L. Koral, Evaporative air Conditioning Handbook, 1997.

[5] Y. M. Xuan et al., "Research and application of evaporative cooling in China: A review (I) - research," Renewable and Sustainable Energy Reviews, vol. 16, no. 5, pp. 3535-3546, 2012.

[6] B. Riangvilaikul and S. Kumar, "An experimental study of a novel dew point evaporative cooling system," Energy and Buildings, vol. 42, no. 5, pp. 637-644, 2010.

[7] V. Maisotsenko et al., Method and Plate Apparatus for Dew Point Evaporative Cooler, Google Patents, 2003

[8] L. Elberling, Laboratory Evaluation of the Coolerado Cooler Indirect Evaporative Cooling Unit, Pacific Gas and Electric Company, 2006.

[9] X. Zhao, J. M. Li, and S. B. Riffat, "Numerical study of a novel counter-flow heat and mass exchanger for dew point evaporative cooling," Applied Thermal Engineering, vol. 28, no. 14-15, pp. 1942-1951, 2008.

[10] C. Zhan et al., "Comparative study of the performance of the M-cycle counter-flow and cross-flow heat exchangers for indirect evaporative cooling - Paving the path toward sustainable cooling of buildings," Energy, vol. 36, no. 12, pp. 6790-6805, 2011.

[11] X. Zhao et al., "Feasibility study of a novel dew point air conditioning system for China building application," Building and Environment, vol. 44, no. 9, pp. 1990-1999, 2009.

[12] X. Zhao et al., "Dynamic performance of a novel dew point air conditioning for the UK buildings," International Journal of Low-Carbon Technologies, vol. 4, no. 1, pp. 27-35, 2009.

[13] B. Riangvilaikul and S. Kumar, "Numerical study of a novel dew point evaporative cooling system," Energy and Buildings, vol. 42, no. 11, pp. 2241-2250, 2010.

[14] X. Cui et al., "Studying the performance of an improved dew-point evaporative design for cooling application," Applied Thermal Engineering, vol. 63, no. 2, pp. 624-633, 2014.

[15] E. D. Rogdakis, I. P. Koronaki, and D. N. Tertipis, "Experimental and computational evaluation of a Maisotsenko evaporative cooler at Greek climate," Energy and Buildings, vol. 70, pp. 497-506, 2014.

[16] X. Zhao, S. Liu, and S. B. Riffat, "Comparative study of heat and mass exchanging materials for indirect evaporative cooling systems," Building and Environment, vol. 43, no. 11, pp. 1902-1911, 2008.

[17] E. Ibrahim, L. Shao, and S. B. Riffat, "Performance of porous ceramic evaporators for building cooling application," Energy and Buildings, vol. 35 , no. 9 , pp. 941-949, 2003

[18] W. Chen, "Thermal analysis on the cooling performance of a wet porous evaporative plate for building," Energy Conversion and Management, vol. 52, no. 5, pp. 2217-2226, 2011.

[19] B. Naticchia et al., "Energy performance evaluation of a novel evaporative cooling technique," Energy and Buildings, vol. 42, no. 10, pp. 1926-1938, 2010.

[20] M. A. Musa, Novel Evaporative Cooling Systems for Building Applications, University of Nottingham, 2009.

[21] J. He and A. Hoyano, "Experimental study of cooling effects of a passive evaporative cooling wall constructed of porous ceramics with high water soaking-up ability," Building and environment, vol. 45, no. 2, pp. 461-472, 2010.

[22] A. Sommers et al., "Ceramics and ceramic matrix composites for heat exchangers in advanced thermal systems - a review," Applied Thermal Engineering, vol. 30, no. 11, pp. 1277-1291, 2010.

[23] D. Y. Lee, J. Jin, and B. Kang, "Momentum boundary layer and its influence on the convective heat transfer in porous media," International Journal of Heat and Mass Transfer, vol. 45, no. 1, pp. 229-233, 2002.

[24] S. B. Riffat and J. Zhu, "Mathematical model of indirect evaporative cooler using porous ceramic and heat pipe," Applied Thermal Engineering, vol. 24, no. 4, pp. 457-470, 2004. 
[25] R. Boukhanouf et al., "Investigation of a sub-wet bulb temperature evaporative cooler for buildings," in Proc. Sustainable Building Conference, Coventry University, 2013.

[26] E. Velasco Gómez et al., "Description and experimental results of a semi-indirect ceramic evaporative cooler," International Journal of Refrigeration, vol. 28, no. 5, pp. 654-662, 2005.

[27] J. W. Wan, J. L. Zhang, and W. M. Zhang, "The effect of heat-pipe air-handling coil on energy consumption in central air-conditioning system," Energy and Buildings, vol. 39, no. 9, pp. 1035-1040, 2007.

[28] F. J. R. Martinez et al., "Design and experimental study of a mixed energy recovery system, heat pipes and indirect evaporative equipment for air conditioning," Energy and Buildings, vol. 35, no. 10, pp. 1021-1030, 2003.

[29] W. B. Beckwith, "Novel application of heat pipes for economical dehumidification in air conditioning systems," American Heat Pipes, Inc. Florida, USA, pp. 1-8.

[30] B. Halasz, "A general mathematical model of evaporative cooling devices," Elsevier, Paris, pp. 245-255, 1998.

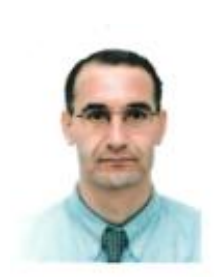

R. Boukhanouf is a lecturer in sustainable energy technologies at the Department of Built Environment, University of Nottingham. His experience in research and teaching in the area of energy efficient and low carbon technologies extends for over 15 years. He obtained his $\mathrm{PhD}$ degree in 1996 from the University of Manchester, UK. Dr. Boukhanouf worked on numerous research projects funded by industry and government agencies in the area of small scale combined heat and power, active and passive heating and cooling systems for buildings, and advanced heat transfer enabling devices. He published a number of journal and conference papers and is named as the inventor in six international patents.

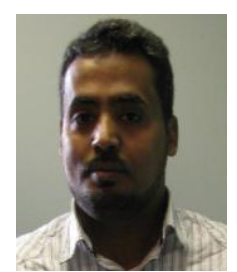

A. Alharbi is a $\mathrm{PhD}$ degree candidate in the Department of the Built Environment, University of Nottingham. His main research topic is evaporative cooling technology in hot and dry climates. Mr. Alharbi has MSc and BEng degrees in mechanical engineering. He has a long industrial experience in air conditioning systems.

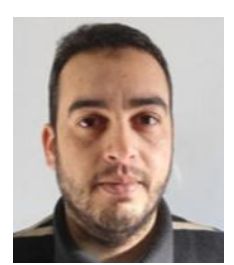

O. Amer is a $\mathrm{PhD}$ degree candidate in the Department of the Built Environment, University of Nottingham. His main research topic is sustainable cooling technologies. Mr. Amer has an MSc degree in new and renewable energies, University of Durham, UK. 2011 BEng degree in mechanical engineering, Misurata University, Libya, 2005.

$\mathrm{He}$ worked as a lecturer at the Mechanical Engineering Department, Faculty of Engineering, Misurata University, Libya from 2011 to 2012.

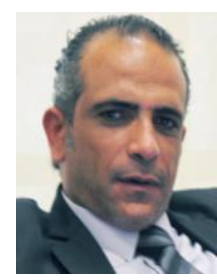

H. G. Ibrahim is an associate professor at Qatar University. Dr. Ibrahim has a long and established research experience including managing green construction, carbon abatement in construction industry using knowledge based programming, and preservation of traditional architectural and urban heritage of Qatar. The latter being particular an ass-on advantage for reconciling the integration of new low carbon technologies with the traditional architectural concepts. 